\title{
Publisher Correction: Short-range interactions govern the dynamics and functions of microbial communities
}

Alma Dal Co Di, Simon van Vliet (D), Daniel Johannes Kiviet, Susan Schlegel and Martin Ackermann

Correction to: Nature Ecology \& Evolution https://doi.org/10.1038/s41559-019-1080-2, published online 10 February 2020.

In the original version of this Article, author Alma Dal Co's name was coded wrongly, resulting in it being incorrect when exported to citation databases. This has now been corrected, though no visible changes will be apparent.

Published online: 16 March 2020

https://doi.org/10.1038/s41559-020-1175-9

(C) The Author(s), under exclusive licence to Springer Nature Limited 2020 